

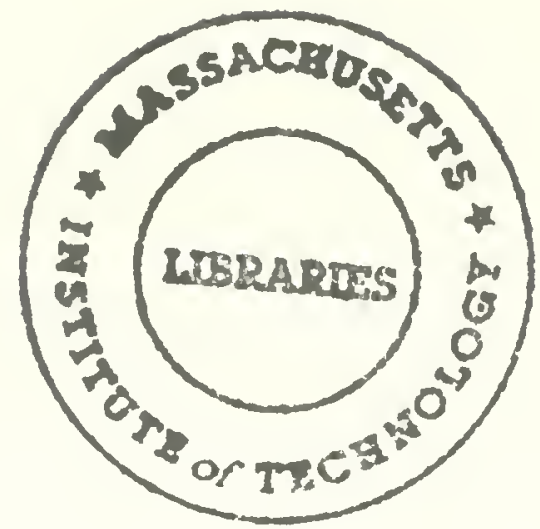






\section{WORKING PAPER}

\section{ALFAED P. SLOAN SCHOOL OF MANAGEMENT}

\section{Research on Strategic Groups: \\ Progress and Prognosis}

Howard Thomas

N. Venkatraman

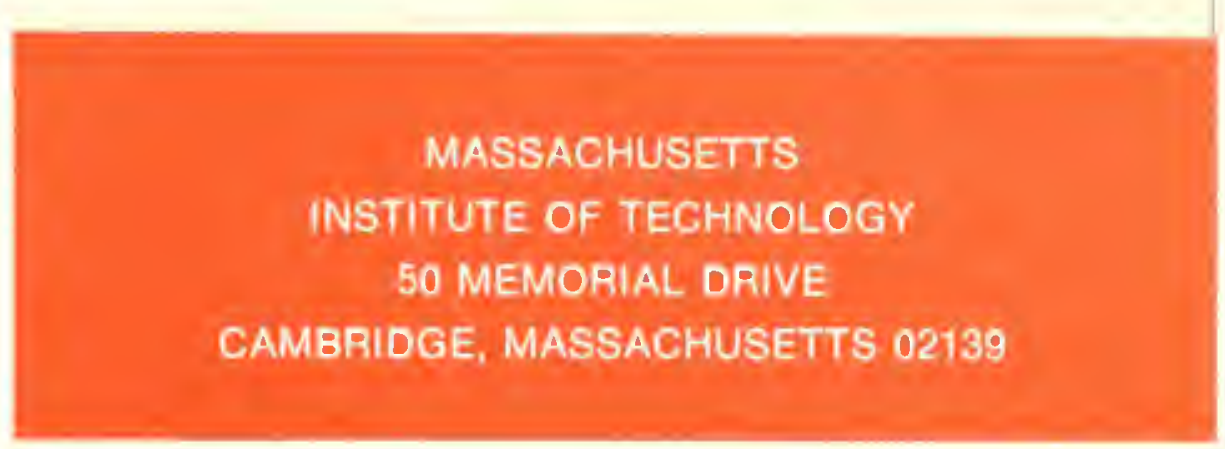




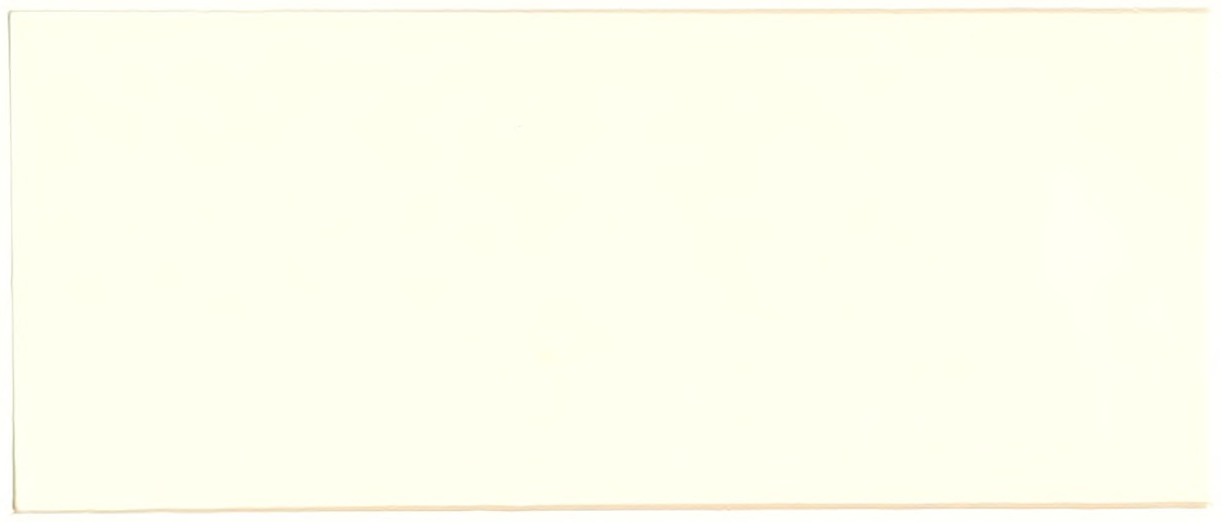


Research on Strategic Groups:

Progress and Prognosis

Howard Thomas

N. Venkatraman

Sloan Working Paper 非1857-87

February 1987 
A I I L

MAR 1. g 1987

RECEIVES 


\title{
Research on Strategic Groups:
}

Progress and Prognosis

\author{
Howard Thomas \\ Massachusetts Institute of Technology \\ and \\ University of Illinois at Urbana-Champaign
}

N. Venkatraman

Massachusetts Institute of Technology

February 1987

Both authors contributed about equally to the discussion. Address all correspondence to: N. Venkatraman, E52-553 Sloan School of Management, MIT, Cambridge, MA. 02139. Phone (617)-253-5044. 

Research on Strategic Groups:

Progress and Prognosis

\author{
ABSTRACT
}

The progress made in the stream of strategic groups research is evaluated by identifying its relevance and importance to the field of strategic management. A classificatory scheme is developed using two dimensions: the operationalization of strategy; and the approach to group development. A review framework incorporating key analytical dimensions is drawn up to (a) identify important summary patterns and (b) develop fruitful research directions from a strategic management perspective. 

Strategic management is a rapidly developing area of research within the management discipline. Much of it is defined and understood in terms of a general paradigm set out in Schendel and Hofer (1979). In addition, it draws upon theoretical concepts from certain relatively-mature disciplines (Jemison, 1981a), which have been recognized as having a significant impact on theory development and testing in strategic management. These include: industrial organization (IO) economics (Porter, 1981); organization theory and administrative behavior (Jemison, 1981b); marketing (Biggadike, 1981), and financial theory (Bettis, 1983; Duhaime \& Thomas, 1983; Meyers, 1984). Somewhat less frequently, strategy researchers also draw upon concepts and research methodological advances from other disciplines such as sociology, psychology, and decision-sciences (see Thomas, 1984 for an overview).

Such a multi-disciplinary orientation is generally considered to be very healthy and appropriate for the growth and development of the strategic management field. However, it is important to recognize that a key to success lies in the ability to adapt the concepts from the parent discipline(s) to the specific needs and requirements of strategic management research. Since concepts derive their meaning through their specific definition, use, and operationalizations, their transferability is a difficult, but challenging task. In recent times, the concept of strategic groups (borrowed from the IO economics discipline) has occupied a prominent role within strategic management (see McGee \& Thomas, 1986; Porter, 1980; 1981). However, the concept and its potential for influencing strategic management research is broader than that envisaged in the IO economics literature.

The purpose of this paper is to review the progress made in the strategic groups literature and identify important issues and research directions from a 
strategic management perspective. Thus, the perspective taken here is one of strategic management and not that of IO economics. Accordingly, our position closely follows that of Hunt, who coined the term--strategic groups as an intermediate level of analysis to explain competitive rivalry observed in an in-depth analysis of the home appliance industry. He defined it as: "A group of firms within an industry that are highly symmetric... With respect to cost structure, degree of product differentiation, degree of vertical integration, and the degree of product diversification... formal organization, control systems, and management rewards and punishments... (and) the personal views and preferences for various possible outcomes..." (1972; p.8).

While many strategy researchers implicitly accept such a definition, there does not seem to be any uniformity in the treatment of strategic groups in empirical research settings. A variety of methods have been used to derive groupings in empirical research settings, which makes any exercise at accumulation of research findings an almost impossible task. However, recognizing that this is an important research stream, this paper aims to: (a) develop a taxonomy for classifying the available empirical research on strategic groups; (b) review the research stream through an analytical framework to identify important patterns in this research stream; and (c) suggest some specific directions for strategic group research from a strategic management perspective. 


\section{Towards a Classificatory Scheme}

It is fairly evident that the general concept of strategic groups holds much promise for strategic management -- which can be seen in the increasing number of conceptual and empirical papers that are grounded in this theme (see McGee \& Thomas, 1986). However, there is as yet no one dominant view of strategic groups that is widely accepted. As Kuhn noted: ". In the absence of a paradigm or some candidate for paradigm, all of the facts that could possibly pertain to the development of a given science are likely to seem equally relevant. As a result, early fact-gathering is far more nearly random activity than the one that subsequent development makes familiar" (1970; p.15). Hence, a useful starting point is to identify and classify the dominant perspectives in the treatment of strategic groups in empirical research.

\section{A Two-Dimensional Scheme}

We propose a classificatory scheme for organizing the empirical research on strategic groups using two dimensions -- (a) the operationalization of strategy; and (b) the approach adopted for the development of groups. The rationale for selecting these two dimensions is set out below.

The choice of the first dimension reflects our belief that the explanatory power of the strategic group concept is fundamentally dependent on the strength of the scheme adopted to operationalize strategy. If the aim is to delineate distinct groups of firms that are "maximally similar" within a group and "maximally different" across groups, in terms of their "strategies", then a critical building block is the operationalization of strategy. However, we do recognize that the general issue of operationalizing and measuring strategy continues to be a topic of considerable concern and discussion (see 
Ginsberg, 1984; Hambrick, 1980; Snow \& Hambrick, 1980; Venkatraman \& Grant, 1986); and there does not seem to be any consensus about how we should classify the various approaches for operationalizing strategy. Hence, in viewing this dimension of the classificatory scheme, we merely distinguish between those studies that have operationalized strategy in narrow terms (say, focusing on one functional area or one dimension) versus those that viewed strategy in relatively broader terms (say, multiple functional areas or multi-dimensional reflecting scope and resource deployment decisions). Such a distinction parallels the notion of the "parts" versus the "holistic" view of Hambrick (1980) and is analogous to the general distinction between "unidimensional" versus "multidimensional" view of strategy. Our position is that the development of strategic groups using a narrow conceptualization of strategy is unlikely to reflect the complexity of the strategy construct, thus limiting the usefulness of strategic groups for both descriptive and predictive purposes.

The other dimension of the scheme focuses on the researcher's approach to the development of groups. Some researchers specify the characteristics of the group a priori, based on extant theoretical rationale (and subsequently may employ data-analytic techniques to confirm or validate their theoretical groupings). In contrast, others derive the grouping structure a posteriori based on empirical results on a specific data set. The former reflects a deductive approach to strategic group development (i.e., theory-driven), while the latter reflects an inductive approach (i.e., data-driven) perspective. Both are legitimate approaches, with their own set of assumptions, strengths, and limitations. Our argument is that this distinction is central to comprehend the meaningfulness of the group structure and for deriving insights for theory construction in strategic management. 
Based on these two dimensions, a four-celled classificatory scheme is developed in Figure 1. The four cells of the scheme imply distinct perspectives on the treatment of strategic groups in empirical research. The four cells are: (a) strategic groups defined a priori based on theoretical considerations using a narrow operationalization of strategy which subsequently may be confirmed empirically: Type I; (b) strategic groups developed empirically (i.e., a posteriori description) using a narrow operationalization of strategy: Type II; (c) strategic groups defined a priori using a broader operationalization of strategy which subsequently may be confirmed empirically: Type III; and (d) strategic groups developed empirically using a broader operationalization of strategy: Type IV.

Insert Figure 1 About Here

Analytical Review Framework

As a supplement to the above taxonomic scheme, which provides a "first-cut" classification, we employ an analytical framework to systematically review the empirical research and uncover important summary patterns that can be subsequently used to suggest future directions. The analytical dimensions of the review framework are briefly described in the following paragraphs.

Operationalization of Strategy. As noted earlier, the power of the strategic group is a function of the operationalization scheme. In this dimension, the details of the operationalization scheme are presented to assess the approaches and the diversity of strategy constructs adopted by researchers to define strategy within the context of developing grouping schemes. The aim 
is to evaluate if the operationalization scheme limits the ability of a particular research study to provide useful insights.

Sampling Frame. Our main purpose in including this dimension in the review framework is to identify whether the data are drawn from a single industry or across multiple industries. The single-industry perspective could reflect strategic dimensions that are idyosyncratic to that industry, while a multi-industry study could employ more general dimensions of strategy and uncover more general patterns of groups. Our expectation is that if consistent patterns of strategic groups (i.e., groups with similar characteristics across different industries) emerge, it could perhaps be a starting point for developing a "unified" theory of strategic group formation, and for examining more focused relationships rooted in the strategic group concept.

Performance. We include performance as an important dimension of the review framework. Our aim is to distinguish between those studies that are concerned with the identification and description of the groups per se from those studies that focus on the implications of these groups for some other criterion variable, such as performance. Since strategic management is centrally concerned with issues of organizational performance (Schendel \& Hofer, 1979) and strategies are often evaluated in terms of their performance implications, it is important that this dimension be reflected in strategic groups research. Our argument, in other words, is that if strategic groups are to be truly useful for theory construction in strategic management, then they should be related to criteria reflecting multiple measures of business- and organizational-level performance. 
Data-analytic Scheme. This dimension sheds light on the approach adopted by researchers to develop groups. Some employ rule-of-thumb clustering approaches to specify grouping (without the aid of statistical techniques), while others use statistical methods to discover the groupings. The former reflect a more intuitive and judgement-based approach while the latter reflects a relatively more systematic approach to specifying the groupings. The use of this dimension also provides the opportunity to identify the range of multivariate techniques that have been employed to discern the grouping structure.

The review based on the above set of dimensions, and organized around the four types identified using Figure 1 , is summarized in Table 1.

Insert Table 1 about Here

\section{Observations}

We summarize the major patterns below, while urging readers to derive additional trends and insights by further analyzing Table 1.

Observation One: No Industry Is Homogeneous!

Most studies reviewed here appear to have as their first (and in most cases, the only) goal to establish that the chosen industry (or industries) is heterogeneous and that distinct groupings can be identified based on a given set of strategic characteristics. Specifically, the Type II studies have dominated this stream covering a range of industries such as airlines (Ryans \& Wittink, 1985), brewing (Hatten \& Hatten, 1985), investment banking (Hayes, Spence, \& Marks, 1983), and office equipment (Baird \& Sudharshan, 1983). The 
typical approach seems to have been to consider a particular industry, identify a set of strategic dimensions and employ one of the data-reduction techniques, obtain a set of groupings, interpret them in the light of their scores along the dimensions used to cluster them, and provide rather weak interpretations of the meaning of the groups for theory or practice.

Given the initial interest within the IO economics field to demonstrate the heterogeneity of an industry, we are not surprised that several studies have adopted this focus. However, from a contemporary strategic management perspective, this may be a non-issue! Most of us implicitly subscribe to a view that firms differ in their strategies but not to an extent that all are so unique that they car not be sorted into homogeneous classes. Indeed, the notion of generic strategies (Niles \& Snow, 1978; Porter, 1980) builds on this view. Hence, any empirical demonstration of the mere existence of some grouping within an industry is not a significant research result within strategir. managenent, unless the grouping structure can be related to extant theory.

Observation Two: Implicit Acceptance of Prespecified Boundaries of Industry A related observation to the above pertains to the definition of an "industry". Defined in terms of the Standard Industrial Classification (SIC) scheme, the "industry" has been for a long time the generally accepted unit and level of analysis in I0 economics (Bain, 1956; Scherer, 1980). Yet even economists (Chamberlain, 1951; Robinson, 1956) have questioned the imprecision in industry definition and the 'fuzziness' of industry boundaries in economic environments characterized by product differentiation and technological change. Within strategic groups research, several studies have implicitly subscribed to the predefined boundaries of an industry. However, if strategic 
management is concerned with the efficient and effective process of alignment between the organization and its environment (Andrews, 1980; Bourgeois, 1980), there are less reasons to be bound to a SIC scheme that mainly reflect product variations. It may be more appropriate to regard the concepts of market and industry as complementary and to adopt a more comprehensive definition of business and competition that captures variations in product, market, and technology (Abell, 1980) as well as reflects competition in the input (scarce resources of production and other inputs), process (technology) and the more conventional notion of output-based competition. Hence, limiting one's attention to SIC classifications for isolating strategic groups may be overly restrictive.

In this context, it is important to note that the selection of industries for strategic groups analysis has mainly been restricted to those that are populated primarily by single/dominant-business firms. As an example, the airlines industry consists largely of firms operating in airlines and related businesses, which makes the data aggregation/disaggregation issue in relation to strategic choice variables and performance a less problematic issue.

Similar advantages exist in the other industries studied (e.g., brewing, office equipment, investment banking, etc.). However, given the increasing trend towards diversification, and consolidation of industries, very few industries are likely to be populated exclusively by single- and dominant-business firms.

A trend away from the use of industry boundaries is to use "environmental types", which begins to reflect the notion of competition across groups. This can be seen in the recent attempts to identify groups of firms (or businesses) that are following "similar" strategies but are situated in environments that cut across the boundaries of industries. In this stream, the aim is to 
identify strategic taxonomies (akin to strategic groups) within a homogeneous environment (akin to an industry). This approach is useful from a theory building point of view, namely for evaluating strategy-performance relationships within and across different environmental profiles (see Hambrick, 1983; 1984; Miller \& Friesen, 1984 for details).

Observation Three: No Consistent Pattern in Group Characteristics

There does not appear to be any consistent pattern in the characteristics of groups across the different studies reviewed here. We attribute this mainly to non-uniformity in the choice of variables used for the development of groups. In some studies, the groups are based on size differences only (see for instance, Porter, 1979), others are based on geographical coverage (Hatten \& Schendel, 1977; Schendel \& Patton, 1978), while some others are based on specific features of the product market (see for instance, Hayes, Spence, \& Marks, 1983).

Thus, one can not meaningfully compare and aggregate the results across different studies. In contrast, had the studies been anchored around a common theme of operationalizing strategy (such as Porter's generic types or Miles and Snow's types; or using a more precise definition of groups that reflect the broader set of strategy dimensions such as scope and resource deployment), it would have been possible to systematically see patterns across studies. From a cumulative, theory-building perspective, there are significant benefits from using a generically applicable scheme.

Observation Four: Lack of Clarity in the Description of Groups

A disappointing observation is that the studies do not provide strong evidence of "descriptive validity" -- i.e., descriptions of the groups in such 
a way that establishes that groups are internally homogeneous and maximally different from other groups. Although there are no well-established criteria for describing the groups, it is generally accepted that the major characteristics are: (a) each group is composed of firms (or, businesses) that follow similar strategies; (b) firms within a group resemble one another more closely than any other firm outside the group; and (c) firms within a group are likely to respond similarly to a market opportunity (or a threat). However, no empirical research study has developed groupings in such a way to satisfy all the three criteria. When groups are defined a priori through indepth analysis of the industry, researchers might have taken some of these criteria into account, but empirical demonstration of adherence to these criteria have not been forthcoming. The implication is that groups may reflect nothing more than statistical homogeneity, at best.

Observation Five: Weak Evidence of Performance Variations Across Groups

A complementary theme to "descriptive validity" is that of "predictive validity", namely the use of grouping structure to systematically predict an extraneous criterion. Within strategic management, a widely accepted criterion is that of performance. The link to performance is important from two points of view. If distinct groups do not show statistically significant variations in performance, the results can be taken as supportive of the view that "generic" strategies that have equal performance effects are operative, and thus providing support for the well-known equifinality principle. In addition, this might suggest that attention should be focused on 'within-group' differences in performance and hence, on the differential set of skills and assets of the different players. Alternatively, if distinct performance differences were observed, then important strategy--environment contingency relationships can be specified and tested. 
Two important patterns emerge. One is that a major proportion of studies have reflected performance as a criterion variable in the research design and have observed differences across groups. It is encouraging to see the concern for predictive validity. The other important pattern is that performance is treated largely in terms of profitability as opposed to a broader conceptualization (Venkatraman and Ramanujam, 1986). Thus, we can only conclude that the evidence of differential performance across strategic groups is limited to profitability differences. While, it is encouraging to see a trend towards reflecting multiple performance measures (e.g., Dess \& Davis, 1984) as well as risk-adjusted measures (see Cool, 1985; Fiegenbaum, 1986), researchers need to pay attention to the issue of relevance and appropriateness of the performance measures to the specific context of the study (e.g., service versus manufacturing sectors).

\section{Suggested Directions}

\section{Explicit Rationale for Expected Groupings}

An important area for further theorizing pertains to the development of a strong, explicit rationale for expected groupings. Given a data matrix (a set of businesses or firms along a set of variables), it is not difficult for numerical taxonomic methods to derive statistically significant groupings. But the groupings may not reflect any strong theoretical or managerial utility. Given that the demonstration of the heterogeneous nature of industry is not the prime focus, one should have reasons for expecting groupings. Thus, the focus should be on deductive theorizing about the number of groups as well as their characteristics rather than exploratory derivation of a set of groups. This issue is particularly significant given that the inherent bias in cluster 
analytic programs and methods is in favor of uncovering groups. Although several methods are available for evaluating the "number of clusters problem" (Milligan \& Cooper, 1985), the question is one of evaluating the superiority of a n1-cluster solution over a n2-cluster solution. Thus, the critical test of evaluating a n1- or n2-cluster solution over the base of a zero-cluster solution is usually never attempted.

For this task, the multi-disciplinary perspective of strategic management may prove to be useful. Theories of 10 economics may provide useful approaches for understanding the market structure (using concepts such as entry-mobility barriers, and exit barriers; product differentiation, concentration, etc.) and thereby posit reasons for expecting heterogeneity. Further, marketing concepts related to product-market definition, customer needs and wants as well as choice preferences and buyer behavior could be overlayed to refine the arguments for the existence or absence of groups. Similarly, the literature on organization theory and administrative sciences provides useful pointers in relation to the differences in organization structure, management systems as well as organizational cultural factors that may have close relationships to strategic choices and actions.

In a somewhat different role, population ecology and notions of organizational species (McKelvey, 1983) provide useful pointers and arguments as to why the groups form, and the correlates of the stability of the groups over time. The challenge from a strategic management perspective is the reconciliation of these somewhat competing viewpoints towards an explicit rationale that can be used as the starting point for research studies in this stream. If this is accomplished, then future research can examine not only the existence of groups at a single point in time but also the evolution of groups over time. 


\section{Richer Operationalization of Strategy}

Strategic groups research is handicapped by inadequate attention to operationalization and measurement issues. Most studies have used surrogates like size to reflect strategy (see Hunt, 1972; Newman, 1978; Porter, 1979) or functional level variables reflecting marketing (Hatten \& Hatten, 1985), or finance (e.g., Baird \& Sudharshan, 1983). If we subscribe to a view that strategy concept is truly integrative and extends beyond that of a single functional area, then we should seek to develop operationalizations that reflect the interrelationships among the functional strategies rather than the individual functional strategies per se.

By richer operationalizations, we mean those that are powerful enough to reflect the complexities of the construct. Good examples are given by Cool (1985), Fiegenbaum (1986), and Fombrun and Zajac (1987). It is well accepted that the concept of strategy is a complex one, and it is naive to expect that the complexities can be captured using simplistic schemes without sacrificing properties of validity and reliability. Our call for a richer and systematic operationalization of strategy for strategic group development is parallel to Mckelvey's (1978) call for the development of organization types using multiple dimensions, Hambrick's (1984) as well as Miller and Friesen's (1984) call for the development of strategy gestalts; and builds upon Venkatraman and Grant's (1986) discussion calling for improvements in the measurement of strategy in general. 
Explore Managerial Perceptions for Group Development

A closely-related theme to the earlier call for a richer operationalization of strategy pertains to the potential that exists to explore managerial perceptions for the development of groups. Important initial contributions have been made by Dess and Davis (1984), Porac, Thomas, and Emme (1985), and Fombrun and Zajac (1987). An important referent for this stream of research is whether the groups make sense to the managers competing in that industry, or more generally, the product-market arena. It could well be that an insignificant set of strategic variables have been used to develop groups -which may not be insightful for managers.

This requires two specific actions. One is to corroborate the results obtained in studies following Type II and Type IV approaches with managerial judgements and perceptions regarding their relevance and use. Specifically, it should be recognized that studies in these two cells should attempt to "validate" their grouping structure with external sources such as managerial perceptions. In the absence of such validation attempts, the richness of the results is seriously eroded. The other action calls for using managerial perceptions as the input data for developing groups. A promising data-analytic approach would be to use multidimensional scaling techniques to develop groups on the basis of similarities of strategies along a set of underlying dimensions (see Kelly, 1955; Porac et.a1., 1985). In such an approach, one is not bound by any disciplinary orientation in the selection of variables. The dimensions can be derived from the analysis and could provide an entirely different configuration of grouping than the one envisioned by the researcher. 
View Strategic Groups as a Means Towards an End

Our last and perhaps the most important suggestion is to view that the formation of strategic groups is a means towards addressing a set of important strategy research questions. In the I0 economics research area, the concept of strategic groups has been used to demonstrate the heterogeneous nature of an industry and to explain intra-industry variations in performance. In strategic management research, the role should be to offer insights into important relationships that may not be otherwise forthcoming.

Some of the research questions from a strategic management perspective that can be addressed using the generalized concept of strategic groups are: (a) determinants of grouping structure -- that goes beyond the $\mathrm{IO}$ economics explanation and incorporates relevant concepts from other disciplines such as marketing, organization theory, population ecology, etc.; (b) stability of grouping structure -- that reflects not only the changes in the market structural characteristics but also firm-specific desires to move across groups to compete more effectively; and (c) the predictive ability of group structure -- to predict either future strategic behavior and/or performance.

Criteria for an Effective Design of a Strategic Group Study

Based on our review, we derive what we believe to be an important set of criteria for designing future studies rooted in this topic and from a strategic management perspective. We recognize that not all the criteria may be satisfied in every design, but this should serve as a useful referent. 
1. Justification of the Sample Frame. An SIC-based industry definition that has routinely served to demarcate the sample domain in previous studies should not be implicitly accepted. At the business strategy level, the focus is on the competitive marketplace which in many cases is not isomorphic with the definition of product-based industry boundaries. For instance, the boundaries among the various financial services-based industries have blurred in recent years due to various technological and regulatory factors. Consequently, the justification of the sample domain emerges as an important design criterion in this stream of research.

2. Operationalization of strategy. Particular care must be taken to ensure that the operationalization of strategy en route to group development reflects the following: (a) link with the key bases of competition in the marketplace (i.e., key success factors that form the basis for effective strategy development and which can be confirmed by a panel of industry experts); (b) relationship to some of the common theoretical discussions on strategy types so that a cumulative perspective can be developed; and (c) basic measurement criteria of reliability and validity. A trend in this direction would serve to enhance the usefulness of strategic groups for theory building.

3. Theoretical Anchors. The study should be anchored in theoretical positions that reflect the reasons for expected groupings. We do not advocate the complete abandoning of exploratory analysis within strategic groups. However, it is necessary to pay particular attention to both prior theorizing as well as post-hoc reconciliation of groupings with extant work. In the absence of theoretical anchors (in this area of research as well as elsewhere) we could be empirically demonstrating a set of findings without a sound reasoning as to why they occurred in that particular form! 
4. Data-analytic Issues. We do not intend to provide any primer on multivariate statistical issues except to note that internal stability of the cluster analytic results is essential. Since cluster analysis is an exploratory data analytic technique, it is important to be particularly sensitive to the issues such as the number of clusters, and the need to cross-validate the solution within subsample analyses.

5. Interpretation of Groups. Interpetability concerns whether the strategic groups observed make sense to strategists and other interested parties. This can be achieved at two levels -- one, through an evaluation of the dimensions used to develop groupings by the concerned managers or industry observers; and the other through an assessment of the output, namely the grouping structure observed. We do not advocate any particular preference at this stage, as long as some attempt at incorporating managerial perceptions is brought into this stream, which is largely characterized by "far-removed" secondary analysis of an available data set.

6. Link to an External (Criterion) Variable. We have emphasized before the need to use strategic groups as a starting point in strategy research rather than as an end. Thus, it is important to identify useful criterion variables that can be related to strategic groups. We suggest two possibilities. One is the use of performance measures (in their multi-dimensional form) to discern performance differences across groups (see Venkatraman and Ramanujam, 1986 for a recent discussion on measurement of performance issues in relation to strategy research). The other candidate for a criterion variable is future strategic behavior that can be predicted from the group composition. Here, one should be able to establish that the group formation serves to isolate possible future behavior. 
Our expectation is that an explicit consideration of these criteria would go a long way in enhancing the quality and usefulness of research studies in this area.

\section{CONCLUSIONS}

The concept of strategic groups is broader than that envisaged in the I0 economics for explaining intra-industry variation in profitability. This paper reviewed the body of research on strategic groups using an analytical framework to uncover important patterns. Suggestions for enhancing this stream of research from a strategic management perspective are provided including a set of criteria for effectively designing a strategic group study. 


\section{References}

Abell, D. F. (1980) Defining the business: Starting Point of Strategic Planning. Englewood Cliffs, NJ: Prentice-Hall.

Aldrich, H. E. (1979) Organizations and environments. Englewood Cliffs, Nu: Prentice-Hall.

Andrews, K.R. (1980) The concept of corporate strategy. Homewood, I11, Richard D. Irwin.

Bain, J. S. (1956) Barriers to new competition. Cambridge, Mass.: Harvard University Press.

Baird, I. S., \& Sudharshan, D. (1983) Strategic groups: A three mode factor analysis of some measures of financial risk. Working Paper 931, Bureau of Business and Economic Research, University of Illinois at Urbana-Champaign.

Bettis, R. A. (1983) Modern financial theory, corporate strategy, and public policy: Three conundrums. Academy of Management Review, 8 , 406-415.

Biggadike, E. R. (1981) The contributions of marketing to strategic management. Academy of Management Review, 6, 621-632.

Caves, R. E., \& Porter, M. E. (1977) From entry barriers to mobility barriers. Quarterly Journal of Economics, 91, 241-261.

Caves, R. E., \& Pugel, T. (1980) Intra-industry differences in conduct and performance: Viable strategies in U.S. manufacturing industries New York University monograph.

Chamberlin, E.H. (1951) Monopolistic competition revisited, Economica, 343-362.

Cool, K. (1985) Strategic group formation and strategic group shifts: A longitudinal analysis of the US pharmaceutical industry, 1963-82 Ph.D Dissertation, Purdue University.

Dess, G. G., \& Davis, P. S. (1984) Porter's (1980) generic strategies as determinants of strategic group membership and organizational performance. Academy of Management Journal, 27, 467-488.

Fiegenbaum, A. (1986) Dynamic aspects of strategic groups and competitive Strategy: Concepts and empirical examination in the insurance industry. Ph.D Dissertation, University of Illinois at Urbana-Champaign.

Frazier, G. L., \& Howell, R. D. (1983) Business definition and performance. Journal of Marketing, 47, 59-67.

Fombrun, C. \& Zajac, E. (1987) Structural and perceptual influences on intraindustry stratification. Academy of Management Journal (forthcoming).

Ginsberg, A. (1984) Operationalizing organizational strategy: Toward an integrative framework. Academy of Management Review, 9, 548-557.

Hambrick, D. C. (1980) Operationalizing the concept of business-level strategy in research. Academy of Management Review, 5, 567-575.

Hambrick, D. C. (1983) An empirical typology of mature industrial-product environments. Academy of Management Journal, 26, 213-230.

Hambrick, D. C. (1984) Taxonomic approaches to studying strategy: Some conceptual and methodological issues. Journal of Management, 10, 27-41.

Harrigan, K. R. (1980) Strategies for declining business. Lexington, Mass.: D. C. Heath \& Co.

Harrigan, K. R. (1985) An application of clustering for strategic group analysis. Strategic Management Journal, 6, 55-73. 
Hatten, K. J., \& Hatten, M. L. (1985) Some empirical insights for strategic marketers: The case of beer. In H. Thomas \& D. M. Gardner (Eds.). Strategic marketing and management, Chichester: John Wiley.

Hatten, K. J., Schendel, D. E. (1977) Heterogeneity within an industry: Firm conduct in the U.S. brewing industry, 1952-1971. The Journal of Industrial Economics, 26, 97-113.

Hatten, K. J., Schendel, D. E., \& Cooper, A. (1978) A strategic model of the U.S. brewing industry: 1952-1971. Academy of Management Journal, $21,592-610$.

Hawes, M. J., \& Crittenden, F. W. (1984) A taxonomy of competitive retailing strategies. Strategic Management Journal, 5, 275-287.

Hayes, S. L. III, Spence, A., \& Marks, D. V. P. (1983) Competition in the investment banking industry. Cambridge, Mass.: Harvard University Press.

Henderson, B. D. (1979) Henderson on corporate strategy. Cambridge, Mass: Abt Books.

Hergert, M. (1983) The incidence and implications of strategic grouping in U.S. manufacturing industries. Unpublished doctoral dissertation, Harvard University.

Hofer, C. W. \& Schendel, D. E. (1978) Strategy formulation: Analytical concepts. New York: West Publishing Co.

Hunt, M. S. (1972) Competition in the major home appliance industry, 1960-1970. Unpublished doctoral dissertation, Harvard University.

Jemison, D. B. (1981a) The importance of an integrative approach to strategic management. Academy of Management Review, 6, 601-608.

Jemison, D. B. (1981b) The contributions of administrative behavior to strategic management. Academy of Management Review, 6, 633-642.

Kelly, G.A. (1955) Psychology of personal constructs. Vol I and II. New York: W.W. Norton.

Kuhn, T. S. (1970) The structure of scientific revolutions. 2nd Ed., Chicago: The University of Chicago Press.

Lahti, A. (1983) Strategy and performance of a firm: An empirical examination in the knitwear industry in Finland, 1969-81. Helsinki, Finland.

Lawrence, P. R. \& Lorsch, J. W. (1967) Organization and environment. Boston: Graduate School of Business Administration, Harvard University.

McGee, J., \& Thomas, H. (1985b) Strategic groups, industry structure and strategic management. Strategic Management Journal, 7, 141-160.

McKelvey, B. (1978) Organizational systematics: Taxonomic lessons from biology. Management Science, 24, 921-933.

Miles, R. E., \& Snow, C. C. (1978) Organization strategy, structure and process. New York: McGraw-Hi 11 .

Milligan, G. W., \& Cooper, M. C. (1985) An examination of procedures for determining the number of clusters in a data set,. Psychometrika, 50 , 159-179.

Miller, D. \& Friesen, P. H. (1978) Archetypes of strategy formulation. Management Science, 24, 921-933.

Miller, D. \& Friesen, P. H. (1984) Organizations: A quantum view. Englewood $\mathrm{Cliffs,} \mathrm{NJ}$ : Prentice-Hall.

Mintzberg, H. (1978) Patterns in strategy formation. Management Science, $24,934-948$.

Myers, S. C. (1984) Finance theory and financial strategy, Interfaces $14(1), \quad 126-138$.

Newman, H. H. (1978) Strategic groups and the structure-performance relationship. Review of Economics and Statistics, 60, 417-427. 
Oster, S. (1982) Intraindustry structure and the ease of strategic change. Review of Economics and Statistics, 64, 376-383.

Pfeffer, J. \& Salancik, G. R. (1978) The external control of organizations: A resource dependence perspective. New York: Harper \& Row.

Porac, J., Thomas, H., \& Emme, B. (1985) Cognitive taxonomies in a retailer's understanding of the competitive environment Working Paper 1215, Bureau of Business and Economic Research University of Illinois at Urbana-Champaign.

Porter, M. E. (1979) The structure within industries and companies' performance. Review of Economics and Statistics, 61, 214-219.

Porter, M. E. (1980) Competitive strategy. New York: The Free Press.

Porter, M. E. (1981) The contributions of industrial organization to strategic management. Academy of Management Review, 6, 609-620.

Porter, M. E. (1982) Cases in competitive strategy. New York: Free Press.

Primeaux, W. J. (1983) The interdependence of the life cycle and strategic group concepts: Theory and evidence. Faculty Working Paper 961, Bureau of Business and Economic Research, University of Illinois at Urbana-Champaign.

Primeaux, W. J. (1985) A method for determining strategic groups and life stages of an industry. In H. Thomas \& D. M. Gardner (Eds.). Strategic marketing and management. Chichester: John Wiley.

Ramsler, M. (1982) Strategic groups and foreign market entry in global banking competition. Unpublished doctoral dissertation, Harvard University.

Robinson, J. (1956) The industry and the market, Economic Journal, $66,360-361$.

Rumelt, R. (1981) Towards a strategic theory of the firm. Paper presented at the Conference on Non-traditional Approaches to Policy Research, University of Southern California, Los Angeles. (Also reprinted in R. Lamb (Ed.) (1984) Competitive strategic management, Englewood Cliffs: Prentice-Hall).

Ryans, A. B., \& Wittink, D. R. (1985) Security returns as a basis for estimating the competitive structure in an industry. In $H$. Thomas \& $D$. M. Gardner (Eds.). Strategic marketing and management. Chichester and New York: John Wiley.

Schende 1, D. E., \& Hofer, C. W. (Eds.) (1979) Strategic management: A new view of business policy and planning. Boston: Little, Brown \& Co.

Schendel, D. E., \& Patton, G. R. (1978) A simultaneous equation model of corporate strategy. Management Science, 24, 1611-1621.

Scherer, F. M. (1980) Industrial market structure and economic performance, Chicago: Rand McNally.

Venkatraman, N., \& Grant, J. H. (1986) Construct measurement in organizational strategy research: A critique and proposal. Academy of Management Review, $11,71-87$.

Venkatraman, N., \& Ramanujam, V. (1986) Measurement of business performance in strategy research: A comparison of approaches. Academy of Management Review, 11, 801-814. 
Figure 1: A Classificatory Scheme for

Strategic Groups Research

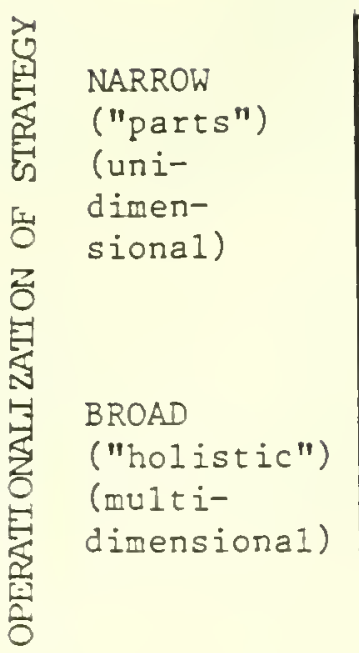

Description. A priori

definition using a narrow

conceptualization of

strategy, and may be

empirically supported

(I)

Description. Empirical

development using a narrow

conceptualization of

strategy

Description. A priori

definition using a broader conceptualization of

strategy, and may be

empirically supported

(III) (IV)
a priori
A posteriori

(Theoretically specified

and may be empirically

(Eppirically derived)

supported)

APPROACH TO GROUP DEVELOPMENT 


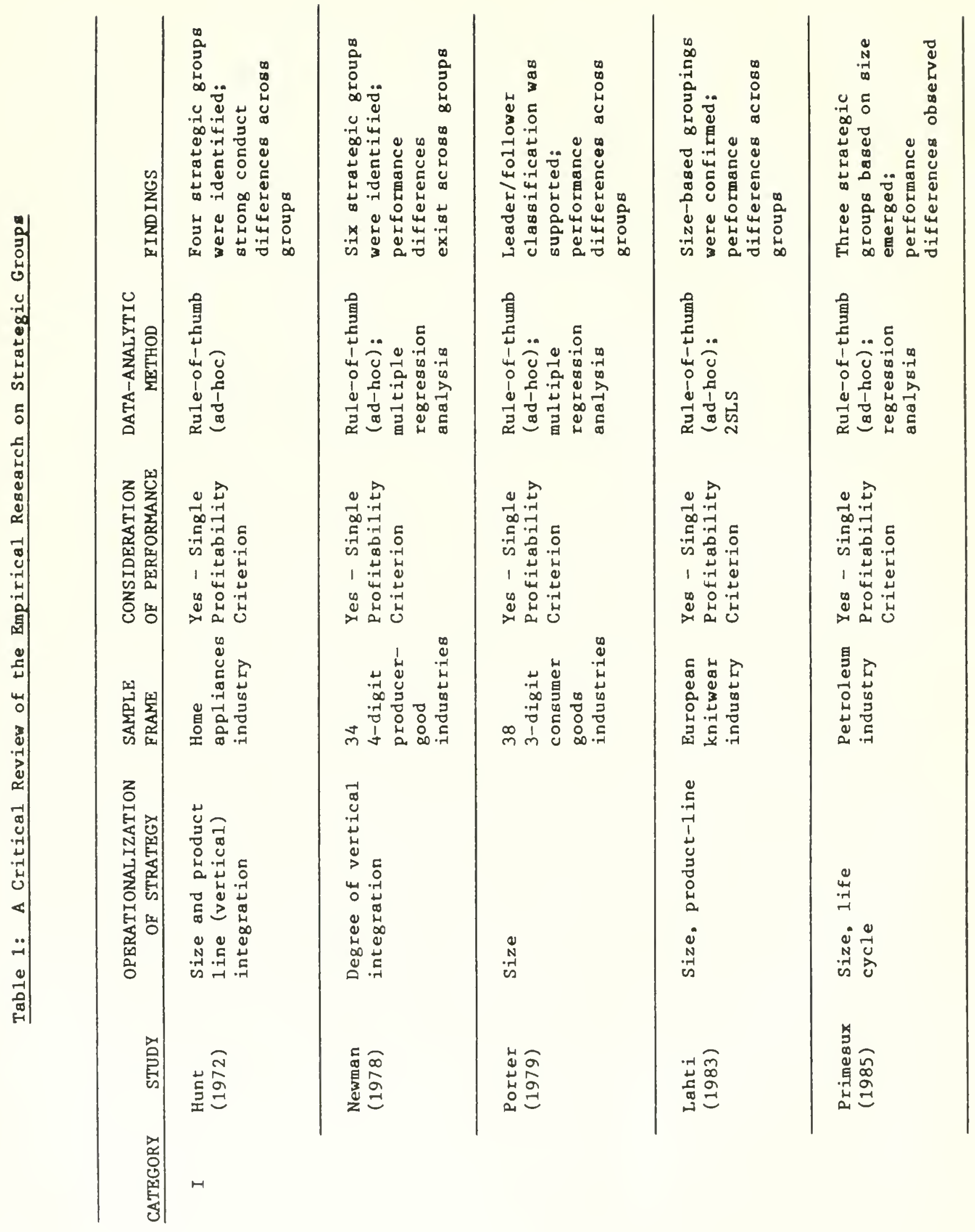




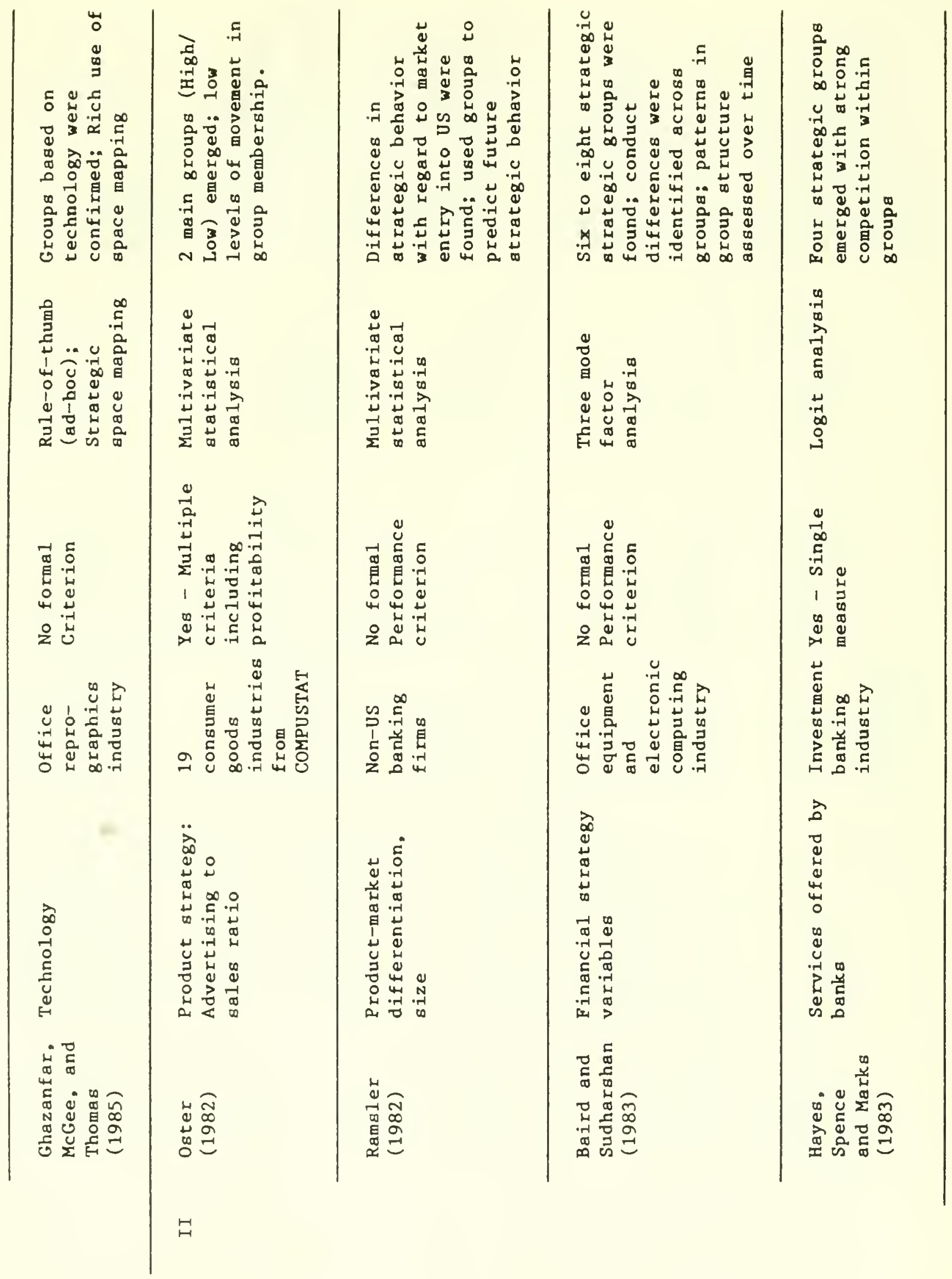




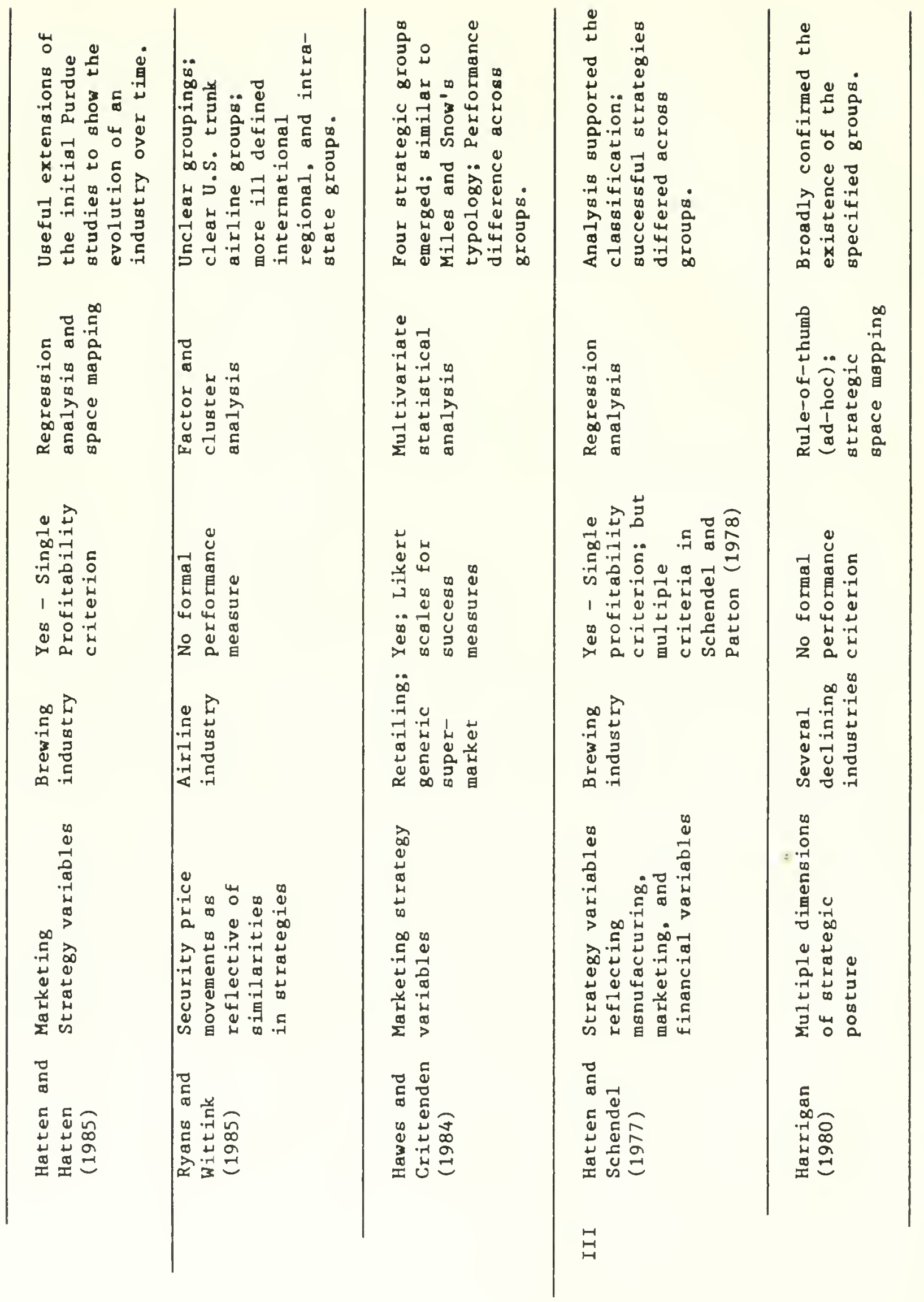




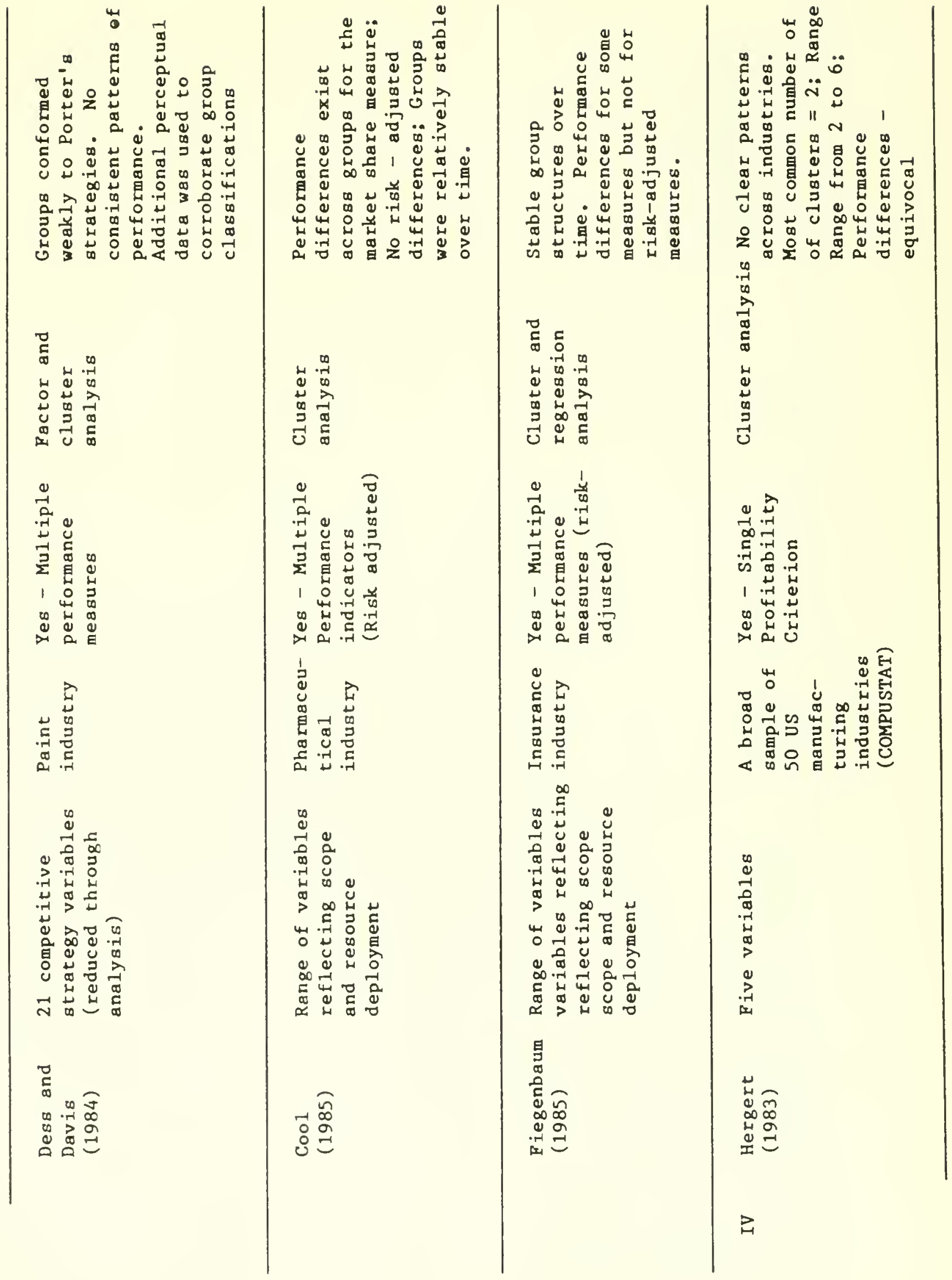




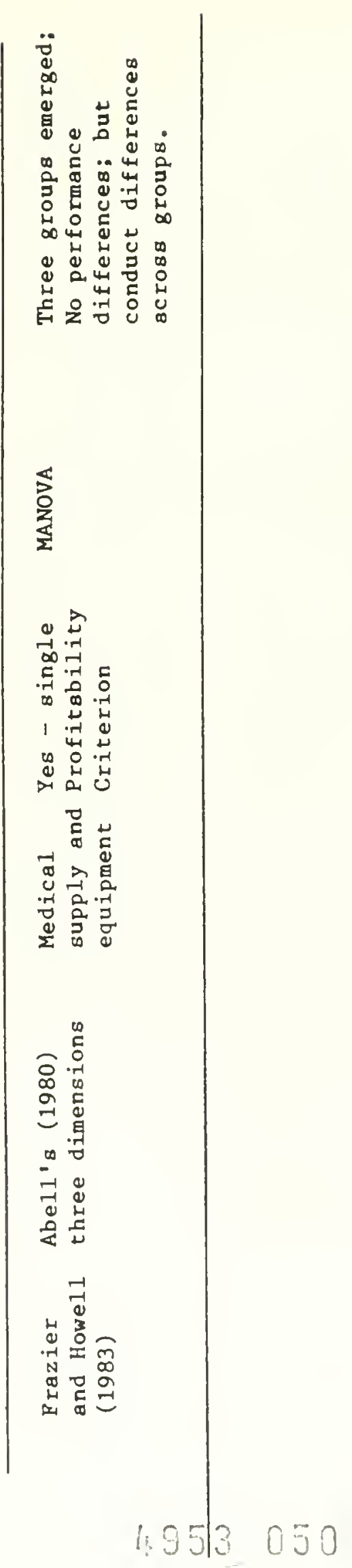







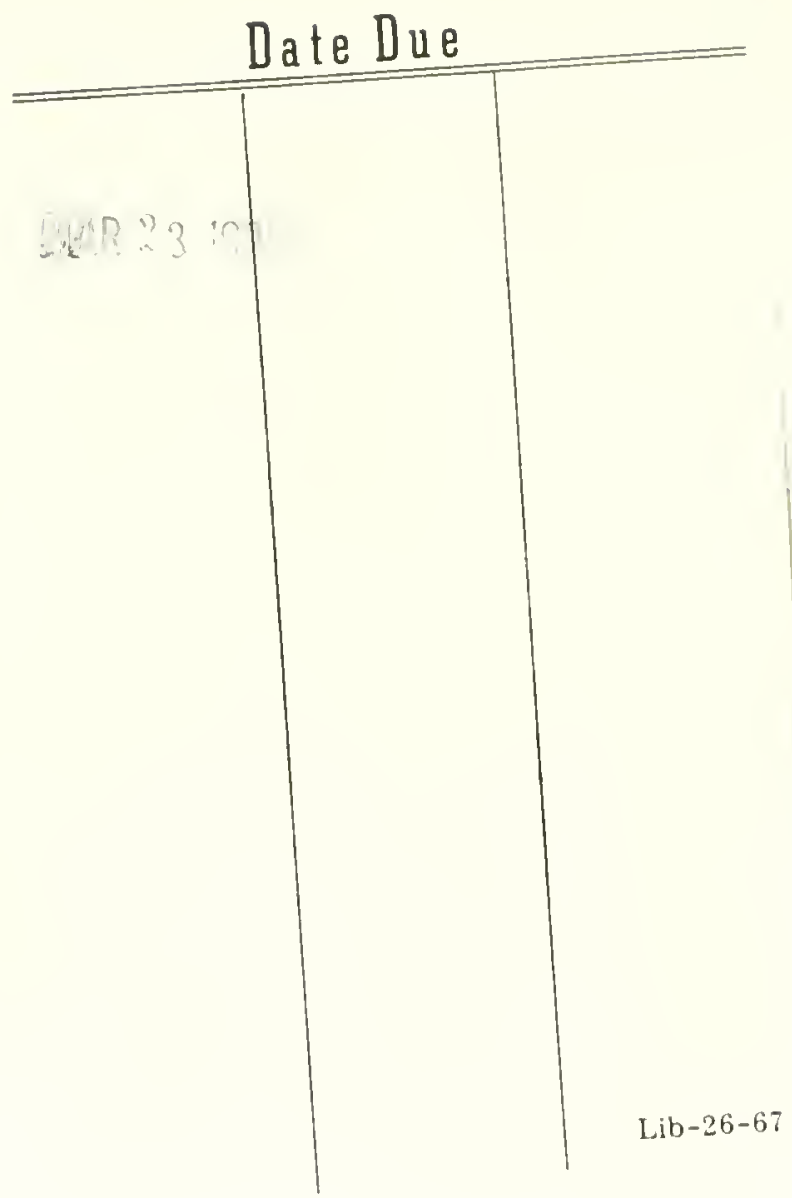




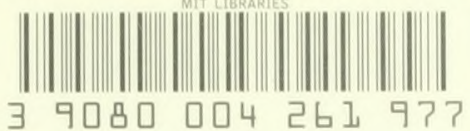


4

6

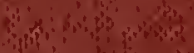

(n) 